\title{
Uzaktan Eğitime Özgü Beden Eğitimi Dersi Temel Psikolojik İhtiyaçlar Ölçeği Geliştirme Çalışması
}

\author{
Elif Nilay ADA *
}

Öz

$\mathrm{Bu}$ çalışmanın amacı uzaktan eğitim yoluyla yapılan beden eğitimi dersindeki temel psikolojik ihtiyaçları değerlendirebilen bir ölçek geliştirmektir. Araştırmaya yaşları 11-15 ( $\mathrm{x}_{\text {yaş }}=12.41$, ss $\left.=.89\right)$ arasında değişen 494 ortaokul öğrencisi $\left(\mathrm{n}_{6 \text {.smıf }}=177, \mathrm{n}_{7 . \text { snıf }}=119, \mathrm{n}_{8 \text {.Sinıf }}=198\right)$ çevrimiçi platformda hazırlanan formu doldurarak katılmıştır. Elde edilen bulgularda, Açımlayıcı Faktör Analizi aracılığıyla 9 maddeli 3 faktörlü bir yapı ortaya çıkmıştır. Bu yapı toplam varyansın \%73.03'ünü açıklayabilmiştir. Faktörlere ait iç tutarlık değerleri ise, Yeterlik boyutu için .81, İlişkili olma boyutu için .77 ve Özerklik boyutu için .83 iken, ölçeğin toplamı için .90 'dır. Ardından yapılan doğrulayıcı faktör analizi sonuçlarında elde edilen uyum indeksleri ise $\mathrm{x}^{2}=84.12$, $\mathrm{sd}=23 ; \mathrm{x}^{2} / \mathrm{sd}=3.65, \mathrm{NNFI}=.98, \mathrm{CFI}=.99, \mathrm{SRMR}=.04, \mathrm{RMR}=.06, \mathrm{AGFI}=.93, \mathrm{GFI}=.96, \mathrm{RMSEA}=.07$ şeklinde ortaya çıkmıştır.

Sonuç olarak, Uzaktan Eğitime Özgü Beden Eğitimi Dersi Temel Psikolojik İhtiyaçlar Ölçeği’nin geçerli ve güvenilir bir araç olduğu söylenebilir. Ölçek, öğrencilerin temel psikolojik ihtiyaçlarını pandemi koşullarında belirleyebilen ve Türk kültürüne özgü geliştirilmiş bir ölçektir

Anahtar Kelimeler: Pandemi dönemi, Beden eğitimi, Uzaktan eğitim, Temel psikolojik ihtiyaçlar, Ölçek geliştirme

\section{The Study on the Development of The Basic Psychological Needs Scale Specific to Distance Physical Education}

\begin{abstract}
The aim of this study is to develop a scale that can determine the basic psychological needs in physical education lessons through distance education. 494 middle school students aged between 11-15 $\left(\mathrm{x}_{\text {age }}=12.41\right.$, $\mathrm{df}=.89)$ participated $\left(\mathrm{n}_{6 \text { th grade }}=177, \mathrm{n}_{7 \text { th grade }}=119, \mathrm{n}_{8 \text { th grade }}=198\right)$ in the study by filling out the form prepared on the online platform. In the findings obtained, a 3-factor structure with 9 items emerged through Explanatory Factor Analysis. This structure could explain 52.08\% of the total variance. The internal consistency values of the factors are .81 for the Competence dimension, .77 for the Relatedness dimension and .83 for the Autonomy dimension, while it is .90 for the total of the scale. The fit indices obtained in the results of the Confirmatory Factor Analysis performed afterwards appeared as $\mathrm{x}^{2}=84.12, \mathrm{df}=23 ; \mathrm{x}^{2} / \mathrm{df}=3.65, \mathrm{NNFI}=$ $.98, \mathrm{CFI}=.99, \mathrm{SRMR}=.04, \mathrm{RMR}=.06, \mathrm{AGFI}=.93, \mathrm{GFI}=.96, \mathrm{RMSEA}=.07$.

As a result, it can be said that the Basic Psychological Needs Scale Specific to Distance Physical Education is a valid and reliable tool. The scale is developed specifically for Turkish culture that can determine the basic psychological needs of students under pandemic conditions.

Keywords: Pandemic period, Physical education, Distance education, Basic psychological needs, Scale development
\end{abstract}

\footnotetext{
* Mersin Üniversitesi, Spor Bilimleri Fakültesi, Mersin-Türkiye, elifnilayada@gmail.com, https://orcid.org/0000-00028817-6136
} 


\section{GIRIŞ}

Yaşantımız 2020 yılının ilk aylarından itibaren dramatik bir şekilde değişti. Dünyanın her yerinde insanlar ortak bir sorun ile benzer şekillerde mücadele vermeye başladı. Günlük rutinimizde çok önemli yere sahip olan okula, işe, tatile yada akraba/arkadaşlara gitme eylemlerimizin hepsi bir anda hayatımızdan çıkarıldı. Sınırlar kapatılarak, tüm hareketlilik kısıtlandı. Pek çok eylem artık çevrim içi yapılarak, insanları fiziksel olarak biraraya getirmeyecek şekilde yeniden tasarlandı. Bu yeniden tasarımda en büyük değişiklik okullarda gerçekleştirildi. Tüm dünyada tüm kademelerdeki eğitim uzaktan yapılmaya başlandı. Eğitimin aksamaması adina uzaktan yapılmaya başlanan eğitim, şuan tüm dünyada pek çok açıdan eleştirilse de, eğitimin devamı açısından en iyi alternatif olarak karşımıza çıkıyor. Ancak beden eğitimi dersi açısından bakıldığında durumun oldukça etkisiz olduğuna yönelik ortak bir kanıdan bahsedebiliriz.

Beden eğitimi dersi bağlamsal açıdan düşünüldüğünde, pek çok dersten farklı özellik gösterir. Beden eğitimi dersi öğrenciyi fiziksel olarak geliştirmesinin yanında sosyal, bilişsel ve duyuşsal olarak da geliştirir (Filiz, 2019). Beden eğitiminin sosyalleşmek, beceri sergilemek, oyun oynamak, özgüven kazanmak, saygı göstermek, rekabet etmek, iş birliği yapmak, takım olabilmek ve yaşam boyu spor alışkanlğı kazanabilmek gibi pek çok yararından bahsedebiliriz (GarcíaHermoso ve ark., 2020; Ryan ve Deci, 2020). Çünkü beden eğitimi dersi bu ve benzeri amaçlara ulaşabilmek için bir araç olarak işlev görür. Ancak uzaktan yapılmaya çalışılan beden eğitimi derslerinde öğrencilerin, yukarıda bahsedilen yararlara ne kadar ulaşabildikleri merak konusudur. Hareket etme ihtiyacının büyük bir kısmının karşılandığı okul ortamından uzak kalma ve beden eğitimi derslerinin uzaktan eğitim ile evlerde yapılması öğrencilerin temel psikolojik ihtiyaçları olan yeterlik, özerklik ve ilişki olma durumlarını yeniden belirleme ihtiyacı oluşturmuş ve buna yönelik bir ölçüm aracı geliştirmek bu araştırmanın amacı olarak belirlenmiştir.

Temel Psikolojik İhtiyaçlar (Basic Psychological Needs), Hür İrade Kuramı'nın
(Self-determination Theory) alt1 mini kuramından biridir ve insanların uyum, bütünleşme ve gelişmesi için psikolojik bir besin olarak tanımlanır (Ryan, 1995). Temel psikolojik ihtiyaçların giderilmesi, kişilerin psikolojik iyilik (well-being) durumlarını sağladığı; giderilmemesi ise olumsuz ruh hali, pasiflik, ve hayal kırıklığ gibi duygu durumlarını ortaya çıkarmayı kolaylaştırdığ belirtilmiştir (Ryan ve Deci, 2000; Vansteenkiste ve Ryan, 2013). Temel psikolojik ihtiyaçlar litertatürde geniş yer bulur ve bunlar özerklik, ilişki olma ile yeterlik olarak tanımlanmışlardır (Deci ve Ryan, 2000). Bu ihtiyaçlardan özerklik, irade ve isteklilik deneyimini ifade eder. Bu ihtiyaç giderildiğinde, kişi eylemleri, düşünceleri ve duyguları arasında bir bütünlük duygusu yaşar. Hayal kırıklığına uğradığında ise kişi bir baskı hissi yaşar ve istenmeyen bir yöne itilmiş hissi gibi bir çatışma yaşar. Diğer kavram olan ilişkili olma ise sicaklık, bağlanma ve ilgi deneyimini ifade eder; ayrıca kişi başkalarına bağlanarak ve onların anlamını hissederek tatmin olur. Bundaki başarısızlık ise, sosyal yabancılaşma, dışlanma ve yalnızlık duygusunu getirebilir. Son kavram olan yeterlik ise, etkililik ve ustalık deneyimi ile ilgilidir. Kişiler beceri ve uzmanlığı kullanma ve genişletme firsatlarını deneyimleyerek, aktivitelerde yetenekli olduklarını hissettiklerinde tatmin olurlar. Ancak kişiler burada hayal kırıklığına uğrarsa, etkisizlik, hatta başarısızlık ve çaresizlik hissi yaşayabilirler (Vansteenkiste ve Ryan, 2013). $\mathrm{Bu}$ üç temel psikolojik ihtiyacın farklı kültürlerdeki insanların sağlıklı gelişimininde çok önemli bir role sahip olduğunu ortaya koyan pek araştırma olduğu gibi (Slemp, Kern, Patrick, ve Ryan, 2018; Vasquez et al., 2016; Yu, Levesque-Bristol, ve Maeda, 2018), bu ihtiyaçların giderilememesi durumlarında uyumsuzluklar ve işlev bozuklukları oluştuğunu ortaya koyan çalışmalar da vardır (Ryan, Deci ve Vansteenkiste 2016). Hür İrade Kuramında, ayrıca güdülenme türleri vardır, ki bunlar güdülenmenin eksikliğini ifade eden motivasyonsuzluk (amotivasyon), güdülenme kaynağı kişiye bağlı olmayan dışsal güdülenme ve içsel ilgi ve eğlenmeyi içeren içsel güdülenme şeklinde tanımlanan bir sürekliliğe sahiptir (Ryan ve Deci, 2017). 
İçsel güdülenme, işlevsel olma ve olumlu çıtılarla ilişkilendirilirken, dışsal güdülenme ve güdülenmeme negatif duygu ve çıtılarla ilişkilendirilmiştir (Vasconcellos ve ark., 2020). Hem beden eğitimi dersine özgü (Ada ve ark., 2020; Erturan-İlker, 2014; Ntoumanis, 2002; Sun ve Chen, 2010; Vallerand ve Losier, 1999) hem de spor ortamına özgü yapılan çalışmalarda bu yapıları destekleyen sonuçlar bulunmuştur (Ersöz ve ark., 2012; Kazak, 1995; Kelecek ve ark., 2010). Özellikle özerklik ihtiyacının giderilmesi, beden eğitimindeki bilişsel, duyuşsal ve psikomotor performans ile olumlu yönde ilişkili bulunmuştur (Ntoumanis ve Standage, 2009; Sun, Li ve Shen, 2017).

Beden eğitimi öğretmenleri, öğrencilere bu temel ihtiyaçlarını giderecek bir sınıf iklimi yaratarak onların içsel güdülenme düzeylerini arttırmaya çalışırlar (Cheon ve Reeve., 2013). Ayrıca destekleyici bir öğretmen ve akran grubu da, öğrenciler üzerinde olumlu etkilere sahiptir (Cox ve ark., 2009). Ayrıca Boiche ve ark. (2008) tarafindan yapılan çalışmada beden eğitimi dersindeki sınıf ikliminin, kişilerin motivasyon profillerini etkileyen önemli bir faktör olduğu belirtilmiştir. Ancak pandemi döneminde beden eğitimi öğretmenlerinin etkili bir sınıf iklimi yaratmada bazı olumsuzluklar yaşadıkları düşünülmüş ve öğretmenlerin arzu edilen sınıf iklimini yaratmada önemli bir faktör olan temel psikolojik ihtiyaçların giderilme durumunu belirleyebilecek bir ölçek geliştirmek, bu araştırma kapsamında önemli görülmüştür. Ayrıca literatürde var olan temel psikolojik ihtiyaçlar (özerklik, yeterlik ve ilişkili olma) evrensel olarak kabul edilir ve bu evrensellik, önceki çalışmalarda yüz yüze eğitim koşulları altında kanıt bulmuştur. $\mathrm{Bu}$ nedenle pandemi döneminde, uzaktan eğitime geçilmesi ile beraber bu temel psikolojik ihtiyaçların karşılanma durumunun değişebileceği düşünülmüştür. Geliştirilmek istenen ölçek ile pandemi ile birlikte değişen ders ortamının (uzaktan), öğrencilerin temel psikolojik ihtiyaçlarını karşılayabilme konusunda ne derece etkili olduğu konusu detaylı olarak incelenebilecektir.

\section{Araştırmanın Amacı}

$\mathrm{Bu}$ çalışmanın amacı uzaktan eğitim yoluyla yapılan beden eğitimi dersindeki temel psikolojik ihtiyaçları değerlendirebilen bir ölçek geliştirmektir.

\section{YÖNTEM}

\section{Katılimcular}

Bu çalışmaya yaşları 11 ile $15(\mathrm{x}=12.41$, ss $=.89)$ arasında değișen toplam 494 ortaokul $\left(n_{\mathrm{kz}}=245, \mathrm{x}_{\text {erkek }}=249, \mathrm{k} 1 \mathrm{z}=\% 49\right.$ erkek $\left.=\% 51\right)$ öğrencisi gönüllülük esasına göre katılmıştır. Çalışmaya 6.sınıf $(n=177), 7$. $\sin ı f(n=119)$ ve 8. siniflar $(\mathrm{n}=198)$ dahil edilmiştir. Daha önce hiç yüzyüze ders yapma olanağı bulamadıkları ve çevrimiçi dersleri kıyaslama yapamayacak durumda oldukları için bu çalışmaya 5 . sınıflar dahil edilmemiştir. Çalışma internet üzerinden çevrimiçi form gönderilerek tamamlanmıştır. Çalışma Mersin Ünversitesi Sosyal ve Beşeri Bilimler Araştırmaları Etik Kurulundan (05/04/2021-04) onaylidir.

\section{Veri Toplama Yöntemleri}

Hazırlanan çevrimiçi form belirlenen okullardaki beden eğitimi öğretmenleri ile dijital ortamda paylaşılmış, onlar da öğrencileri ile kurdukları çevrim içi gruplara formu yollayarak gönüllü öğrencilerin onayıyla çalışmaya katılımlarını sağlamışlardır. Ölçeğin yanıtlanması yaklaşık 3-4 dk sürmektedir.

\section{İşlem}

Ölçek maddelerinin yazılması aşamasında hem alan yazın hem de yurt içindeki ve dışındaki temel psikolojik ihtiyaçları ölçen ölçme araçlarındaki maddeler incelenmiştir. Böylece Hür İrade Kuramına ait yapıyı tanımlayabilen 18 maddelik bir madde havuzu oluşturulmuştur. Havuzda, özerklik boyutunda 6, ilişkili olma boyutunda 6 ve yeterlik boyutunda ise 6 madde yer almıştır. Oluşturulan 18 maddelik deneysel form, uzman görüşleri alınmak üzere hem Spor Bilimleri hem de Eğitim Bilimleri alanlarından üçer uzmanın görüşüne sunulmuştur. Uzmanlardan gelen dönütler yardımıyla aday ölçek formu oluşturulmuştur. Uzmanların görüşlerinin alınabilmesi için 3'lü derecelendirme kullanılmıştır. Hazırlanan formda uzmanların her bir madde için "uygun", "kısmen uygun" ve "uygun değil" seçeneklerinden birini seçmeleri beklenilmiştir. Uzman formlarının tamamı tek bir formda birleştirilerek her bir maddenin 
olası seçeneklerine kaç uzman tarafından onay verildiği belirlenmiştir. Bu süreçte uzmanların vermiş olduğu görüşler doğrultusunda maddelerin kapsam geçerliği (Yurdugül, 2005) kapsam geçerlik oranı ile belirlenmiştir. Söz konusu oranlar her bir madde için olumlu yanıt vermiş uzman sayısı toplamının toplam uzman sayısına oranının bir eksiği alınarak belirlenmiştir. Uzman görüşlerinin alınmasından sonra, 14 maddelik bir form belirmiş ve ölçeğe son şekli verilmek üzere diğer değerlendirme aşamalarına geçilmiştir.

\section{Verilerin Analizi}

Araştırmaya katılmayı kabul eden toplam 494 ortaokul öğrencisinden gelen yanıtlar doğrultusunda ölçeğin geçerlik ve güvenirlik analizleri yapılmıştır. Araştırma kapsamında faktör analizinin yapılabilmesi için gerekli görülen örneklem büyüklüğ̈̈ incelenmiş, çalışma grubu yeterli görülmüştür (Tabachnick ve Fidell, 2001). Madde başına en az 20 katılımcı kullanmak önerildiğinden (Kline, 2013), bu çalışmadaki katılımcı sayısının yeterli düzeyde olduğu söylenebilir. "Uzaktan Eğitime Özgü Beden Eğitimi Dersi Temel Psikolojik İhtiyaçlar Ölçeği”nin yapı geçerliğini belirlemek için varimax döndürme ile maksimum olasılık analizi kullanılarak Açımlayıcı Faktör Analizi (AFA) yapılmıştır. Analizde faktör yükleri en az .45 olarak belirlenmiştir (Büyüköztürk, 2006). Ölçeğin alt boyutları ve toplam güvenirlikleri için Cronbach Alpha katsayısı hesaplanmıştır. Ayrica AFA ile ortaya konulan yapının doğruluğunun test edilebilmesi için Doğrulayıcı Faktör Analizi (DFA) yapılmıştır.

\section{BULGULAR}

\section{Geçerliğe İlişkin Bulgular}

Ölçeğin yapı geçerliliğini ortaya koymak ve maddelerin faktör yüklerini belirleyerek boyutlandırabilmek amaciyla faktör analizi yapılmıştır. Faktör analizine başlamadan önce verilerin uygunluğunu saptamak üzere KaiserMeyer-Olkin (KMO) katsayısı ve Barlett
Sphericity testi hesaplanmıştır. KMO değeri .91 bulunmuş ve Bartlett testi sonucu da $(\mathrm{df}=$ $\left.55 / \mathrm{x}^{2}=2333.07, \mathrm{p}=0.000\right)$ anlamlı çıkmıştır (George ve Mallery, 2001). AFA (varimax döndürme) ile faktör yapısının ortaya konma aşamasında alanyazın dikkate alınmış ve faktör yapısı üç ile sınırlandırılmıştır. $\mathrm{Bu} 3$ faktörün ölçeğe ilişkin açıkladığı varyans toplamı ise \%73.03'tür. Hiçbir faktörde yüklenmeyen ve faktör madde yükü .45 'in altında olan 5 madde analizden çıkartılmıştır. Böylece elde edilen ölçek 9 maddeli ve 3 faktörlü bir yapı olarak ortaya çıkmıştır.

Tablo 1'deki t değerleri incelendiğinde, söz konusu faktör yüklerinin istatistiksel olarak anlamlı olduğu görülmüştür. Faktörlerin faktör yükleri $\quad .63$ ile $\quad .83$ arasında değişmektedir. Tüm faktörler toplam varyansın \%73.03'ünü açılayabilmiştir. Birinci faktör toplam varyansın \%54.47'sini açıklamaktadır. Bu faktör "Özerklik" faktörü olarak belirlenmiş olup, ögrencinin irade ve isteklilik deneyimlerini ifade eden maddelerden oluşur (örnek madde: uzaktan yapılan beden ĕgitimi derslerinin ögretilme şekli istediğim gibi). İkinci faktör toplam varyansın \% 11.50'sini açıklamaktadır. $\mathrm{Bu}$ faktör ise öğrencinin diğerlerinin anlam ve önemini hissetme deneyimlerini ifade eden maddelerden oluşur ve faktör adı "İlişkili olma"olarak belirlenmiştir (örnek madde: uzaktan beden eğitimi dersleri ile akadaşlık ilişsilerimin geliştiğini düşünüyorum). Üçüncü faktör ise toplam varyansın \%7.06'sını açıklamaktadır. $\mathrm{Bu}$ faktör ise öğrencinin dersteki ustalık ve etkililik deneyimlerini ifade eden maddelerden oluşur. "Yeterlik" olarak adlandırılan bu faktör ve diğer iki faktör üçer maddeden oluşarak toplamda 9 maddelik bir ölçme aracı elde edilmiştir (örnek madde: uzaktan yapılan beden eğitimi dersi sayesinde, kendimi eskisine göre (pandemiden öncesine göre) sporda daha yetenekli hissediyorum). Analiz sonuçlarına göre işleyen tüm maddelerin planlanan boyutlarda olduğu görülmüştür. 
Tablo 1: Uzaktan Eğitime Özgü Beden Eğitimi Dersi Temel Psikolojik İhtiyaçlar Ölçeği'nin AFA Faktör Yükleri ve DFA'da Ortaya Çıkan $\mathrm{R}^{2}$ ve t Değerleri

\begin{tabular}{lccccccc}
\hline & \multicolumn{2}{c}{ Özerklik } & \multicolumn{2}{c}{ Ilişkili olma } & \multicolumn{2}{c}{ Yeterlik } \\
\hline \multicolumn{1}{c}{ Madde } & AFA & $\mathrm{R}^{2}$ & AFA & $\mathrm{R}^{2}$ & AFA & $\mathrm{R}^{2}$ & t değeri \\
\hline 1 & .68 & .54 & & & & & 18.36 \\
9 & .82 & .62 & & & & & 17.39 \\
13 & .68 & .69 & & & & & 18.98 \\
\hline 10 & & & .81 & .59 & & & 18.34 \\
12 & & .83 & .45 & & & 15.50 \\
14 & & .63 & .55 & & & 17.28 \\
\hline 6 & & & & & .63 & .66 & 20.83 \\
7 & & & & & .69 & .67 & 20.91 \\
8 & & & & & .80 & .46 & 16.12 \\
\hline
\end{tabular}

Tablo 2: Uzaktan Eğitime Özgü Beden Eğitimi Dersi Temel Psikolojik İhtiyaçlar Ölçeği’nin Faktörleri Arasındaki Korelasyon Katsayıları

\begin{tabular}{lccc}
\hline Faktörler & 1 & 2 & 3 \\
\hline Yeterlik & 1.00 & $.617^{* *}$ & $.722^{* *}$ \\
Özerklik & & 1.00 & $.559^{* *}$ \\
İlişkili Olma & & & 1.00 \\
\hline
\end{tabular}

$\mathrm{p}<0.01$

Uzaktan eğitime özgü beden eğitimi dersi faktörleri arasında pozitif anlamlı ilişki temel psikolojik ihtiyaçlar ölçeği’nin olduğu görülmüştür (Tablo 2).

\section{Doğrulayıcı Faktör Analizi}

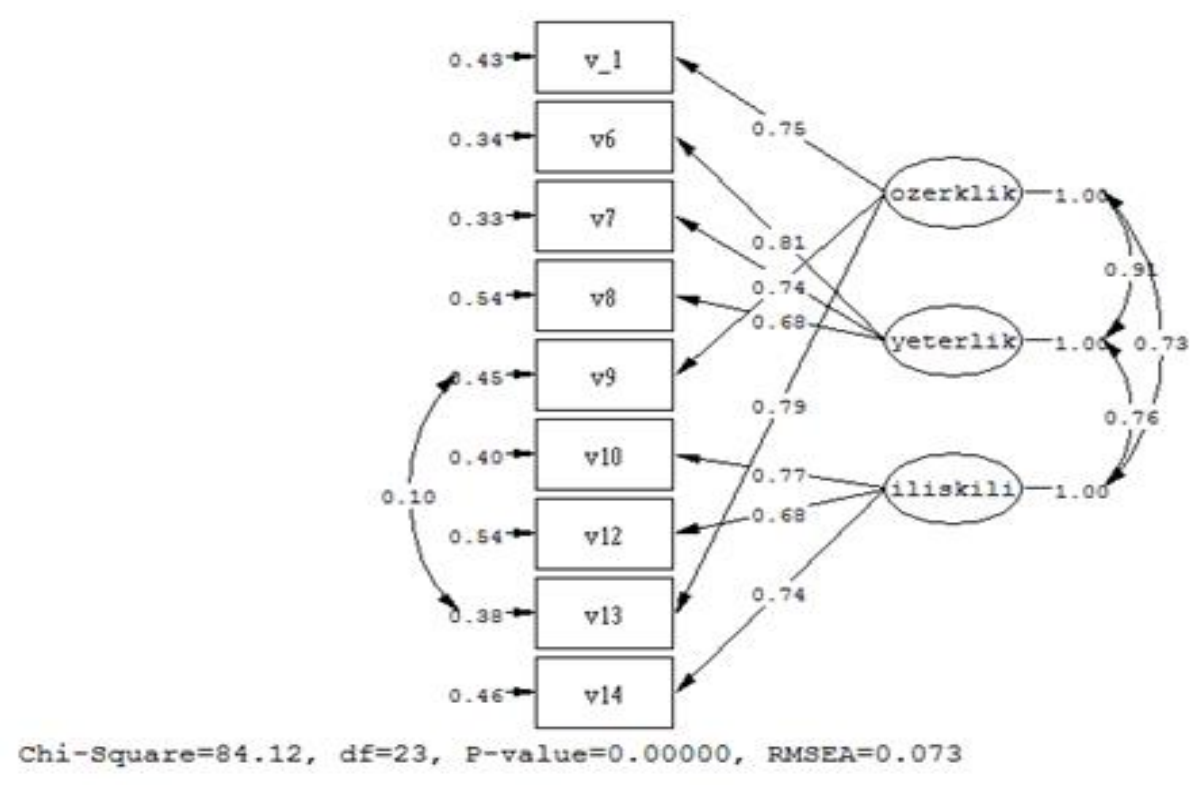

Şekil 1: Uzaktan Eğitime Özgü Beden Eğitimi Dersi Temel Psikolojik İhtiyaçlar Ölçeğine Ait DFA Sonuçları 
Uzaktan eğitime özgü beden eğitimi dersi temel psikolojik ihtiyaçlar ölçeği'nin faktör dağılımının Türk kültürüne özgü yapısı, AFA'da belirlenen yapıyı doğrulamıştır (Şekil 1). Modele ait diğer uyum indeksleri Tablo 3 'te sunulmuştur. Analizde kullanılan uyum indeksleri ve eşik değerleri (Gürbüz ve Şahin, 2018 , s.345) incelendiğinde, ortaya çıkan değerlerin iyi ile kabul edilebilir uyum değerlerine sahip olduğu görülmektedir. Tablo 3'te kabul edilebilir eşik değerleri sunulmuş, $\mathrm{x}^{2} / \mathrm{sd}$ ve RMSEA değerlerinin kabul edilebilir düzeyde, diğer tüm değerlerin ise iyi düzeyde olduğu ortaya konmuştur. Modele ait modifikasyon önerileri incelenmiş, yapının mantığına uyan 9. ve 13. Maddelerin bağlanmasına karar verilmiştir. Modifikasyon öncesi uyum indeksleri $\mathrm{x}^{2} / \mathrm{df}=96.85 / 24$, $\mathrm{NNFI}=.98, \mathrm{CFI}=.98, \mathrm{SRMR}=.04, \mathrm{RMR}=.07$, $\mathrm{AGFI}=.92, \mathrm{GFI}=.96$, RMSEA $=.078$ olarak elde edilmiştir. Modifikasyon işlemi ki-karede 11.4'lük bir azalma sağlayabilmiştir. $\mathrm{Bu}$ azalma yapıya ait diğer uyum indekslerinde dikkate değer bir değişim yaratmasada, modifikasyon işleminden sonraki değerler kabul edilmiştir (Tablo 3).

Tablo 3. Uzaktan Eğitime Özgü Beden Eğitimi Dersi Temel Psikolojik İhtiyaçlar Ölçeği'nin Uyum İndeksleri

\begin{tabular}{lcccccccccc}
\hline Model & $\mathrm{x}^{2}$ & $\mathrm{sd}$ & $\mathrm{x}^{2} / \mathrm{sd}$ & $\mathrm{NNFI}$ & $\mathrm{CFI}$ & SRMR & RMR & AGFI & GFI & RMSEA \\
\hline 3 Faktörlü Yap1 & 84.12 & 23 & 3.65 & .98 & .99 & .04 & .06 & .93 & .96 & .07 \\
Eşik değerleri & & & $<5$ & $>.90$ & $>90$ & $<.08$ & $<.08$ & $>90$ & $>90$ & $<.08$ \\
\hline
\end{tabular}

NNFI=Non-Normed Fit Index-Normlaştırılmamış uyum indeksi; CFI=Comparative Fit index-Karşılaştırmalı uyum indeksi; AGFI= Adjusted Goodness of Fit Index- Düzeltilmiş Uyum iyiliği indeksi; GFI=Goodness of Fit Index- Uyum iyiliği indeksi; RMR= Root Mean Square Residual-Ortalama Hataların Kare Kökü; SRMR= Standardized Root Mean Square Residual- Standartide Edilmiş Ortalama Hataların Kare Kökü RMSEA=Root Mean Square Error of Approximation- Tahminin ortalama karekök hatası.

\section{Güvenirliğe İlişkin Bulgular}

Üç faktörlü 9 maddeden oluşan Uzaktan Eğitime Özgü Beden Eğitimi Dersi Temel Psikolojik İhtiyaçlar Ölçeği'nin güvenirlik katsayıları Cronbach Alpha kullanılarak elde edilmiştir. Buna göre iç tutarlık katsayıları, Yeterlik boyutu için .81, İlişkili olma boyutu için .77 ve Özerklik boyutu için .83 olarak elde edilmiştir. Ölçeğin toplamı için elde edilen güvenirlik katsayısı ise .90 'dır. Elde edilen bu değerler ile Uzaktan Eğitime Özgü Beden Eğitimi Dersi Temel Psikolojik İhtiyaçlar Ölçeği'nin geçerli ve güvenilir bir araç olarak geliştirildiği ortaya çıkmaktadır.

\section{TARTIŞMA ve SONUÇ}

$\mathrm{Bu}$ çalışmada uzaktan eğitim yoluyla yapılan beden eğitimi dersindeki temel psikolojik ihtiyaçları belirleyebilen 9 maddeli ve 3 faktörlü bir ölçek geliştirilmiştir. Sonuç olarak araştırmadan elde edilen bulgular, ölçeğin geçerli ve güvenilir bir araç olduğunu ortaya koymuştur. Uzaktan Eğitime Özgü Beden Eğitimi Dersi Temel Psikolojik Ihtiyaçlar Ölçeği, öğrencilerin temel psikolojik ihtiyaçlarını pandemi koşullarında belirleyebilen bir ölçektir. Ölçek 5'li likert üzerinden yanitlanır $(l=$ kesinlikle katılmıyorum ile 5= kesinlikle katıllyorum), 9 maddelidir ve ters puanlanan madde yoktur. Ölçek ile hem boyutlar bazında hem de toplam puan olarak değerlendirme yapılabilir. Ülkemizde daha önce temel psikolojik ihtiyaçları ölçebilen ölçek uyarlama çalışmaları yapılmış ve bu yönde önemli katkılar sağlanmıştır. Turkay ve ark. (2019) tarafindan beden eğitimi dersine, Kesici ve ark. (2003) tarafından yetişkinlere, Durmaz ve Akkuş (2016) tarafından eğitime, Aşçı ve ark. (2013) tarafından egzersize ve Bülbül ve Akyol (2020) tarafindan spora özgü temel psikolojik ihtiyaçlar ölçeklerinin uyarlamaları yapılarak literatüre kazandırılmıştır. $\mathrm{Bu}$ çalışmalarda ölçeklerin ölçülen yapıya ilişkin 
faktör yapıları belli olduğundan ölçeğin orijinal formuna uygun olarak doğrulayıc1 faktör analizi yapılmıştır. Elde edilen uyum indeksleri bu ölçeklerin kullanılabilir olduğunu ortaya koymuştur.

$\mathrm{Bu}$ çalışmada ayrıca iç tutarlık katsayısı kullanılarak güvenirlik hesaplaması yapılmıştır. Karakoç ve Dönmez (2014)'e göre iç tutarlık, sık başvurulan bir güvenirlik ölçütüdür. Bu çalışmada elde edilen .63 ile .83 arasındaki katsayılar, ölçeğin tek seferde yapılan ölçümle söz konusu kavramsal yapıyı tutarlı bir şekilde ölçebildiğini göstererek, ölçeğin iç tutarlığına ilişkin bir kanıt oluşturabilmiştir (Gürbüz ve Şahin, 2018).

Elde edilen bu ölçek, tamamen Türk kültürüne özgü olduğundan diğer adaptasyon ölçeklere göre özgündür. Maddelerin yazımı aşamasında alan yazın incelenmiş ancak maddeler tamamen yeniden yazılmıştır. Oluşturulan ilk madde havuzu ile ölçeğin 9 maddelik son formunun elde edilme süreci tamamen Türk beden eğitimi dersine, öğrencisine ve öğretmenine yönelik olarak ortaya çıkmıştır. Bu nedenle, bu çalışma ile geliştirilen ölçek, alanda çalışan herkesin rahatlıkla yorumlayabileceği bir yapıya sahiptir. Bir toplumun kendi dilini ve kültürünü doğru olarak yansitabilen ölçeklere sahip olması, diğer kültürlerden uyarlanmaya çalışılan ölçeklerden daha doğru sonuçlar vermesi açısından oldukça önemli görülmüştür.

Ölçek pandemi dönemine özgü olmasından dolayı, kullanımı kısıtlı sayılabilir. Ancak pandemi dönemi bittiğinde yani uzaktan eğitim koşulları bittiğinde de ölçeğin kullanımı farklı konularla ilişkilendirilme yapılarak yada, yüz yüze eğitim koşullarına ait elde edilen verilerle kıyaslama yapılarak sağlanabilir. Bu açıdan hem uzaktan eğitime özgü hem de yüz yüze eğitim koşullarına uygun çok sayida ölçme aracının kazandırılması önemlidir.

Pandemi süresince öğrencilerin hareket etmek, sosyalleşmek ve yeni beceriler ögrenmek gibi firsatları minimum düzeyde deneyimlemeleri, onların duyuşsal, bilişsel ve psikomotor beceri düzeylerinde değişiklik yaratmış olabileceğinden; öğrencilerin bu süreci daha olumlu geçirmeleri sağlanmalıdır. Geliştirilen bu ölçek ile kesitsel çalışmalar yapılabilir ve gerekirse müdahale çalışmaları yapılarak negatif çıktılarla ilişkili olan durumların ortaya çıkmadan önlenmesi sağlanabilir.

\section{Teşekkür}

Yok.

\section{Yazarların Makaleye Katkı Beyanı}

Makale tasarımı, literatür taraması, makale yazımı, dergi yazım kurallarına uygun şekilde düzenlenerek gönderilmesi Elif Nilay ADA tarafindan yapilmıştır.

\section{Çıkar Çatışması}

Yazarın beyan edecek herhangi bir çıkar çatışması yoktur.

\section{Finansal Destek}

$\mathrm{Bu}$ çalışmanın yapılabilmesi için herhangi bir finansal destek alınmamıştır.

\section{Etik Kurul Onayı}

$\mathrm{Bu}$ çalışma Helsinki bildirgesi ile uyumludur. Çalışma Mersin Ünversitesi Sosyal ve Beşeri Bilimler Araştırmaları Etik Kurulundan (05/04/2021-04) onaylidır.

\section{Hakem Değerlendirmesi}

Kör hakemlik süreci sonrası yayınlanmaya uygun bulunmuş ve kabul edilmiştir.

\section{KAYNAKÇA}

Ada, E. N., Comoutos, N., Bal, S. İ., ve Pehlevan, Z. (2020). Beden eğitimi dersine yönelik durumsal güdülenme, tutum ve içsel konuşma arasindaki ilişki. Sport Sciences, 15(4), 53-66.

Boiché, J., Sarrazin, P.G., Grouzet, F.M., Pelletier, L.G., ve Chanal, J.P. (2008). Students' motivational profiles and achievement outcomes in physical education: A self-determination perspective. Journal of Educational Psychology, 100, 688-701. doi:10.1037/0022-0663.100.3.688

Bülbül, A., ve Akyol, G . (2021). Sporda psikolojik ihtiyaçlar durum ölçeği (SPİDÖ): Türkçe uyarlaması, geçerlik ve güvenirlik çalişmasi . Spor Bilimleri Dergisi , 31 (4) , 163-173 . DOI: 10.17644/sbd.782132 
Büyüköztürk, Ş. (2006). Sosyal bilimler için veri analizi: istatistik, araştirma deseni SPSS uygulamalari ve yorum. Ankara: PegemA Yayıncılık.

Cheon, S. H. ve Reeve, J. (2013). Do The benefits from autonomy-supportive pe teacher training programs endure?: A one-year follow-up investigation, Psychology of Sport and Exercise, 14, (4): 508-518, ISSN 1469-0292, https://doi.org/10.1016/j.psychsport.201 3.02 .002

Cox, A., Duncheon, N., ve McDavid, L. (2009). Peers and teachers As sources of relatedness perceptions, motivation, and affective responses in physical education. Research Quarterly for Exercise \& Sport, 80(4), 765-773.

Deci, E. ve Ryan, R. (2000). The "What" and "why" of goal pursuits: Human needs and the self-determination of behavior. Psychological Inquiry. 11. 227-268. 10.1207/S15327965PLI1104_01.

Durmaz M. ve Akkuş, R. (2016). Eğitim alanında öz belirleme kuramı perspektifinden matematik kaygısı, motivasyon ve temel psikolojik ihtiyaçlar. Eğitim ve Bilim 41 (183).

Ersöz, G., Öztürk, M., Kilinç, F., Koşkan, Ö., ve Çetinkaya, E. (2012). Sporcuların güdüsel yönelimlerinin bazi değişkenlere göre incelenmesi. $C B \ddot{U}$ Beden Eğitimi ve Spor Bilimleri Dergisi, 7(1), 15-26.

Erturan-Ilker, G. (2014). Psychological wellbeing and motivation in a Turkish physical education context. Educational Psychology in Practice, 30(4), 365-379.

Filiz, B. (2019). Beden Eğitimi ve spor eğitiminde sosyal sorumluluk programlari ve türkiye'deki yeri. Hacettepe Journal of Sport Sciences, 30 (1), 1-14, doi.org/10.17644/sbd.394546

García-Hermoso A., Alonso-Martínez A. M., Ramírez-Vélez R., Pérez-Sousa M. Á., Ramírez-Campillo R., ve Izquierdo M. (2020). Association of physical education with improvement of healthrelated physical fitness outcomes and fundamental motor skills among youths: A systematic review and metaanalysis. JAMA Pediatr. 174(6) doi:10.1001/jamapediatrics.2020.0223

George, D. ve Mallery, P. (2001). SPSS for Windows: Step by step. Allyn \& Bacon, USA.
Gürbüz, S. ve Şahin, F. (2018). Sosyal bilimlerde araştirma yöntemleri (5. Bask1). Ankara: Seçkin Yayıncılık.

Karakoç, F.Y.ve Dönmez, L.. (2014). Ölçek geliştirme çalışmalarında temel ilkeler. Tıp Eğitimi Dünyast. 13: 39-49. Doi:10.25282/ted.228738.

Kazak, Z. (1995). Sporda güdülenme ölçeğiSGÖ'nin Türk sporculari için güvenirlik ve geçerlik çalışması. Spor Bilimleri Dergisi, 15(4), 191-206.

Kelecek, S., Altıntaş, A. ve Aşçı, F.H. (2010). Motivational orientations of elite volleyball players: Gender and qualification differences. 11th International Sport Science Congress Abstract Book, 10-12 November, Antalya, 102-103, Türkiye.

Kline, R. B. (2013). Exploratory and confirmatory factor analysis, Içinde $\mathrm{Y}$. Petscher ve C. Schatsschneider, (Ed.), Applied quantitative analysis in the social sciences (171- 207). New York: Routledge.

Kesici, Ş., Üre, Ö., Bozgeyikli, H., ve Sünbül, A.M. (2003) Temel psikolojik ihtiyaçlar ölçeğinin geçerlik ve güvenirliği, VII. Ulusal PDR Kongresi Bildiri Özetleri Kitab1, Malatya

Ntoumanis, N. (2002). Motivational clusters in a sample of British physical education classes. Psychology of Sport and Exercise, 3(3), 177-194. doi:10.1016/S14690292(01)00020-6

Ntoumanis, N., ve Standage, M. (2009). Motivation in physical education classes: A self-determination theory perspective. School Field, 7(2), 194202.

Ryan, M. R. ve Deci, E. L. (2020). Intrinsic and extrinsic motivation from a selfdetermination theory perspective: Definitions, Theory, practices, and future directions, Contemporary Educational Psychology, 61, 101860, ISSN 0361-476X, https://doi.org/10.1016/j.cedpsych.2020. 101860.

Ryan, R. M. (1995). Psychological needs and the facilitation of integrative processes. Journal of Personality, 63 ,397-427.

Ryan, R. M. ve Deci, E. L.(2000). Selfdetermination theory and the facilitation of intrinsic motivation, social development, and well-being. The American Psychologist. 55: 68-78. Doi: 10.1037/0003-066X.55.1.68. 
Ryan, R. M., Deci, E. L., ve Vansteenkiste, M. (2016). Autonomy and autonomy disturbances in self- development and psychopathology: Research on motivation, attachment, and clinical process. Içinde D. Cicchetti (Ed), Developmental psychopathology, 1 (pp. 385-438) Hoboken, NJ: John Wiley ve Sons Inc.

Ryan, R. M., ve Deci, E. L. (2017). Selfdetermination theory: basic psychological needs in motivation, development, and wellness. Guilford Publications.

Slemp, G. R., Kern, M. L., Patrick, K. J., ve Ryan, R. M. (2018). Leader autonomy support in the workplace: A metaanalytic review. Motivation and Emotion, 42, 706-724

Sun, H., ve Chen, A. (2010). An examination of sixth graders' self-determined motivation and learning in physical education. Journal of Teaching in Physical Education, 29, 262-277. doi:10.1123/jtpe.29.3.262

Sun,H. , Li, W. ve Shen, B. (2017). Learning in physical education: A selfdetermination theory perspective . Journal of Teaching in Physical Education 36 (3), 277-291

Tabachnick, B. G. ve Fidell, L. S. (2001). Using multivariate statistics (4th Ed). Needham Heights: Allyn ve Bacon

Turkay, H., Mumcu, H.E., Çeviker, A., Güngöz, E. ve Özlü, K.(2019). Beden eğitiminde temel psikolojik ihtiyaçlar ölçeğinin türkçeye uyarlanması. Gazi University Journal of Gazi Educational Faculty (GUJGEF), 39 (2).

Vallerand, R.J., ve Losier, G.F. (1999). An integrative analysis of intrinsic and extrinsic motivation in sport. Journal of Applied Sport Psychology, 11, 142-169. doi:10.1080/10413209908402956

Vansteenkiste, M., ve Ryan, R. M. (2013). On psychological growth and vulnerability: basic psychological need satisfaction and need frustration as a unifying principle. Journal of Psychotherapy Integration, 23, 263-280

Vasconcellos, D., Parker, P. D., Hilland, T., Cinelli, R., Owen, K. B., Kapsal, N., Lee, J., Antczak, D., Ntoumanis, N., Ryan, R. M., ve Lonsdale, C. (2020). Self-Determination theory applied to physical education: A systematic review and meta-analysis. Journal of Educational Psychology, 112(7), 1444-
1469. https://doi.org/10.1037/edu00004 20

Vasquez, A. C., Patall, E. A., Fong, C. J., Corrigan, A. S., ve Pine, L. (2016). Parent autonomy support, academic achievement, and psychosocial functioning: A meta-analysis of research. Educational Psychology Review, 28, 605-644.

Vlachopoulos, S. P., Asci, F. H., Cid, L., Ersoz, G., González-Cutre, D., MorenoMurcia, J. A., ve Moutão, J. (2013). Cross-cultural invariance of the basic psychological needs in exercise scale and need satisfaction latent mean differences among Greek, Spanish, Portuguese and Turkish samples. Psychology of Sport and Exercise, 14(5), 622-631.

Yu, S., Levesque-Bristol, C., ve Maeda, Y. (2018). General Need for autonomy and subjective well-being: A meta-analysis of studies in the US and East Asia. Journal of Happiness Studies, 19, 1863-1882.

Yurdugül, H. (2005). Ölçek geliştirme çalışmalarında kapsam geçerlik indeksinin kullanımı. 14. Eğitim Bilimleri Kongresi, Pamukkale Üniversitesi, Denizli. 